\title{
Effect of Two Different Surface Treatments on Retention of Cosmopost with Two Different Core Materials
}

This article was published in the following Dove Press journal: Clinical, Cosmetic and Investigational Dentistry

\author{
Mohamed A Qudaih' \\ Salah A Yousief ${ }^{1,2}$ \\ Mahmoud NM Allabban' \\ Ali Abkar Mohammed Nejri' \\ Ahmed Mohamed Elmarakby ${ }^{3,4}$ \\ 'Department of Restorative Dental \\ Sciences, AlFarabi Private College for \\ Dentistry and Nursing, Jeddah, Kingdom \\ of Saudi Arabia; ${ }^{2}$ Department of Fixed \\ Prosthodontic, Faculty of Dental \\ Medicine, Al-Azhar University, Assiut \\ Branch, Cairo, Egypt; ${ }^{3}$ Department of \\ Restorative Dental Science, AlFarabi \\ Colleges for Dentistry and Nursing. \\ Riyadh, Kingdom of Saudi Arabia; \\ ${ }^{4}$ Department of Operative Dentistry, \\ Faculty of Dental Medicine, Al-Azhar \\ University, Assiut Branch, Cairo, Egypt
}

Correspondence: Ahmed Mohamed Elmarakby

Tel +966506676440

Email drahmedmarakby@yahoo.com
Objective: The objective of this study was to determine the effect of Cosmopost's two different surface treatments (sandblasting and silica coating) on persistence to various core materials using push-out test set-up.

Material and Methods: A total of 30 Cosmoposts was used in this study. Cosmoposts were divided into three groups (10 samples each) according to the post-surface treatment received. Every category was additionally subdivided into two subgroups according to the type of core material ( $\mathrm{n}=5$ samples). A specially designed copper mold was used for construction of different core materials with standardized dimensions around the posts, in such a way to ensure that the posts will be centralized. Surface roughness was estimated for all Cosmoposts, following different surface treatments using SEM. Cylindrical cores were fabricated of either composite resin or heat-pressed zirconia-containing glass-ceramic (IPS Empress Cosmo, Ivoclar Vivadent). Following the construction of different Core materials, samples were subjected to push-out test set-up to Evaluate the impact of various treatments on post/core bond strength. Data were collected, tabulated and statistically analyzed. SEM was performed on Cosmoposts following debonding of different post/core samples to determine their mode of failure.

Results: Results of push-out bond strength revealed that core material, surface treatment and the interaction between the two variables using Two-way ANOVA had a statistically significant effect on mean push-out bond strength. Regarding the effect of type of core material on Push-out bond strength, results showed that IPS Empress Cores showed statistically significant higher mean push-out bond strength to Cosmopost $(36.4 \pm 9.7 \mathrm{MPa})$ than composite cores $(15.8 \pm 2.5 \mathrm{MPa})$.

Conclusion: Within the limitations of this study, direct heat-pressed ceramic core was more beneficial for zirconia post buildups, than Composite Cores, since they provided higher bond strength. Thanks to a double improvement: increase in fracture resistance and retentive capacity to post. Also, Tribochemical Silicacoating technique was proved to be more effective in Cosmopost treatments than sandblasting technique.

Keywords: sandblasting, Cosmopost, push-out bond strength, IPS Empress

\section{Introduction}

Different dental post-core systems have been proposed. Metal posts were initially utilized. However, the great mismatch between the elastic modulus of metal posts and surrounding structures generally leads to stress concentration and root fracture. Consequently, posts with different shape, size and materials were developed. ${ }^{1}$ Amore favorable stress distribution may be obtained using glass fiber-reinforced posts, which 
have an elastic modulus (45.7-53.8 GPa) lower than those of metal posts (110 GPa for titanium and $95 \mathrm{GPa}$ for gold) and higher than that of dentin $(18.6 \mathrm{GPa})$. It is well known that stress concentration generally occurs at the apical and cervical regions of the tooth and that flexible posts cause stress concentrations in dentin, whereas rigid posts concentrate stresses at the inter-faces. To optimize stress distribution, a post should possess a functionally graded stiffness decreasing from the coronal part to the apical end. This might be achieved with an inhomogenous post design. ${ }^{1}$ Post-core systems made of fiber-reinforced composite resins or zirconiabased ceramics for the nonvital teeth are available for increasing demands for esthetical restorations. ${ }^{2}$ The clinical performance largely relies on the physical and mechanical properties of the core material and consistency between post and the core components. ${ }^{2}$ Zirconia posts may be used with indirect approaches in which a core ceramic glass is directly heated onto a zirconia post. ${ }^{3}$ The concerns associated with this technique include the rigid joint of the core and the post, which results in the localization of stress levels on the interface. ${ }^{3}$ Alternative treatment methods involve moving the ceramic core heat separately to the post with a resin luting agent or applying the resin core directly. Although both techniques have accomplished with improvement in fracture resistance, ${ }^{4}$ composite resins core have significant clinical benefit because they have the ability to bond to the tooth structure in combination with bonding agents, and because they require immediate tooth preparation. ${ }^{5}$ Because zirconia based ceramics cannot be roughened with hydrofluoric acid due to their insufficient silica content, airborne abrasion is the alternative to establish a micromechanical contact between the composite resin and the ceramic surface. The reaction between the silica content of the ceramic substrate and the silane coupling agent, however, depends upon the chemical binding to the ceramic surface. ${ }^{6,7}$ Silane coupling substances are organic-inorganic hybrid compounds which by dual reactivity, may facilitate chemical bonding between organic and inorganic dissimilar materials. ${ }^{8,9}$

\section{Esthetic Posts}

Generally, Fiber posts compose of fibers in a resin matrix, with a silane agent bound between the fibers and the substrate (carbons, quartz, silicone, zirconia, or glass). These posts are widely used in bonding procedures based on bisphenolglycidyl methacrylate (Bis-GMA) and can be cemented using an adhesive technique. ${ }^{10}$ In the early 1990s, the market was flooded with prefabricated, eventually polymerized fiber enhanced composite resin posts. One of the first FRC prefabricated posts was the C-Post (Composipost), a post made of carbon fiber-reinforced epoxy resin, produced in France. $^{11,12}$ The main advantage offered by carbon fiber posts was that they were more flexible than metal posts and had about the same elasticity (stiffness) modulus as dentin. When bonded with resin cement, forces in the root were thought to be distributed more evenly, this led to fewer and better root fractures, frequently repairable. ${ }^{13}$ Meyenberg et al presented zirconia posts first which claimed that their flexural strengths (900-1200 MPa) are close to casting gold or titanium and that the same post measurements as high gold or titanium alloys can be used. ${ }^{14}$ Zirconia is currently a commonly used component in prosthodontics due to its strong chemical consistency, high mechanical strength, high durability, and a Young alloy-like frame. A mechanical feature called toughness conversion is the high initial strength and crack resilience of partly stabilized zirconia. ${ }^{15}$

Zirconia does have an esthetic benefit of being similar to normal teeth colors, apart from its desirable chemical and physical properties. ${ }^{16,17}$ However, from an optimal post zirconia posts will not be removed easily if withdrawing is necessary, since zirconia posts cannot be separated from the root canal if there is a defect. ${ }^{18} \mathrm{~A}$ zirconia post is impossible to remove, yet the removal by ultrasonic activation of a damaged zirconia post has been found to cause postal and root temperature to rise. ${ }^{19}$

\section{CosmoPost}

The prefabricated, cylindro-conical CosmoPosts are made of Zirconium oxide ceramic (ZrO2-TZP1- ceramic), which has been successfully used for medical appliances (hip replacements) for approximately 10 years. The good compatibility, corrosion resistance, and excellent mechanical strength (high flexural strength and fracture toughness) of the $\mathrm{ZrO} 2-\mathrm{TZP}-$ ceramic is particularly valued. ${ }^{20}$ The high temperatures during production result in a high-quality ceramic material, which is free of porosity. Yet, CosmoPosts are contraindicated for patients with bruxism or suspicion of bruxism and deep overbite. If the defined preparation (residual dentine) is not possible or one of the contraindications above is present, a metal post must be used as the risk of post-fracture is significantly increased.

\section{Types of Core Materials} Principles of Core Build-Up

Constructing a core building is necessary with a decrease in residual tooth substance. ${ }^{21}$ Morgano and Brackett, $1999^{22}$ Some of the desired features of a core material 
have been identified and include sufficient compression to withstand forces intraorally, ${ }^{23}$ enough flexural capacity, ${ }^{23}$ Bioconsistency, ${ }^{24}$ withstand oral fluid leakage at the interface between core and teeth, ${ }^{25,26}$ Facility for control, binding to the residual tooth structure, ${ }^{27,28}$ thermal expansion and contraction factor close to dental structure, ${ }^{25}$ stability in dimensions, ${ }^{29}$ less ability for absorption of water ${ }^{30,31}$ dental caries prevention. ${ }^{32}$ However, there is no such perfect core material as the widely used materials all show such strengths and weaknesses. Casting gold, amalgam, resin-based composite and glass ionomer cement are the most commonly used core materials. Since they exhibit high strength and low solubility, several years, both cast gold and amalgam are widely used, because their thermal expansion factor is close to the dental material. In addition, gold and amalgam are not esthetically appealing, especially under the recent restoration of all-porcelain.

\section{Direct Core Materials}

Found to be the three main direct dental core components, silver amalgam, composite and ionomer glass. The characteristics that predict a key material's clinical behavior are the compressive, shear and tensile strengths and the stiffness. ${ }^{33,34}$

\section{Glass ionomer}

In the early 1990s, glass ionomer cements were used as a core material. In a number of studies, it was shown that glass ionomer cement is a poor load-bearing core material. ${ }^{35-38}$ Because of its comparatively low compressive strength, compared to amalgam and composite, it is useful only to block out small defects in vital teeth. ${ }^{39}$ Today, glass ionomer is no longer indicated as a core material due to its low compressive strength compared to other core materials. ${ }^{40,41}$ Furthermore, glass ionomer cement revealed low compressive and tensile strengths, however as a core material in another study it had low fracture resistance. ${ }^{42}$ It also exhibits a low elasticity module, weak dentine and enamel binding properties, low condensability and high solubility.

\section{Composite}

Composite has a compressive strength between the core material of amalgam and glass ionomer, but more flexible than amalgam. ${ }^{23}$ When a suitable bonding agent is used in conjunction with composite, ${ }^{43}$ a high bonding strength to dentine (up to $30 \mathrm{Mpa}$ ) can be achieved. Particularly in the anterior section, it offers an esthetically pleasing material under restoration of all porcelain. Which has good strength and poor solubility properties. When a significant coronal structure remains, composite is considered an acceptable direct core material. ${ }^{34,36,38,44}$ But less attractive if dentin aid is reduced. ${ }^{45}$ Bonding strategies can improve a core's mechanical retention but should not be used as the only retention method. ${ }^{28,45,46}$ A 2-mm ferrules are available on the margins of a safe tooth substance in vitro Pilo $\mathrm{R}$ et al, there was no substantial variation in fracture and failure characteristics among such materials in comparison of resin composite, amalgam and caste gold as core material under a crown in endodontic teeth. ${ }^{47}$ Higher bond strengths for binding zirconia posts to composite resin core materials have been documented compared to prefabricated metals posts. ${ }^{48}$ The consequence was smoother the surfaces of zirconia posts result in lesser macromechanical and micro-mechanical reception of composite resin core materials. ${ }^{48,49}$ Therefore, zirconia posts were more vulnerable to zirconia bonding and composite resin interface adhesive failure.

\section{Indirect Core Materials}

Either pressed directly or constructed and cemented to the post.

\section{CosmoPost with Pressed Core Build-Up}

Edelhoff D and Sorensen JA, ${ }^{2}$ stated that the Build-ups are fabricated from $5-\mathrm{mm}$ diameter acrylic rods. These are bonded to the CosmoPost zirconia posts using cyanoacrylate such that the end surfaces of the post and the core build-up are flush. The patterns are invested in accordance with the IPS Empress method following the instructions of the manufacturer. After preheating to $850^{\circ} \mathrm{C}$, Cosmo Type 2 pressing ceramic is pressed to the post at $900{ }^{\circ} \mathrm{C}$. Then post and core assemblies are divested and jet-cleaned with corundum $(\mathrm{Al} 2 \mathrm{O} 3,50 \mu \mathrm{m})$ at $1 \mathrm{bar}$.

\section{CosmoPost with Cemented Core Build-Up}

Jain et $\mathrm{al}^{50}$ stated that, acrylic core build-ups are constructed around $\mathrm{Zr}$ posts, then removed and invested and the buildups pressed using the CosmoPost ingots in conjunction with the IPS Empress method. After divesting, the surfaces and hole for $\mathrm{Zr}$ post of each build-up are jet-cleaned with $50 \mu \mathrm{m}$ corundum at 1 bar. Etching paste (hydrofluoric acid) used on the surface of the hole (Ivoclar, Schaan, Liechtenstein) for $1 \mathrm{~min}$. After rinsing off the etching gel and drying, the restorations are silaned with Monobond S (Ivoclar) and coated with Heliobond (Ivoclar). Then contact surfaces of the posts were jet-cleaned with corundum and silaned. The 
contact surfaces of the post, as well as the walls of the hole, are lightly coated with Panavia 21 (Kuraray, Osaka, Japan). Finally, the post is inserted into the core build-up using slight rotating movements. Paul SJ and Werder $\mathrm{P}^{51}$ tested the bond strength between the Cosmopost and the IPs Empress Core ingot ceramic constructed with the IPs Empress heat pressing procedure. In the selected test procedure (Schenk testing machine), the posts were forced out of the ceramic core build-up material at an advance rate of $5 \mathrm{~mm} / \mathrm{min}$. The first crack was recorded. A so-called prototype, ie, a zirconium oxide post adhesively bonded to the core build-up, was used as the control group. Results revealed that the zirconium oxide posts bonded with the core build-up by means of the heat-pressing technique demonstrated higher bonding strength than those bonded with an adhesive. This increased bonding strength is particularly notable with untreated zirconium oxide posts. On the other hand, various types of bonds between the post and core build-up were examined by Nothdurft FP and Pospiech PR. ${ }^{52}$ Pressing, adhesive cementation, and milling of the entire structure. The breaking load and the deflection at fracture were measured and compared. The load was exerted perpendicular to the post axis. Results showed that the adhesive cementation of the ceramic build-up onto the ceramic post may be a true alternative to the conventional pressing technique. The elastic bond between the rigid materials provides an additional advantage. The objective of this research was to Assess the impact of two different surface treatments (sandblasting and silica coating) of Cosmopost on retention to different core materials using push-out test set-up.

\section{Materials and Methods}

\section{Materials}

CosmoPost (Ivoclar Vivadent) (Table I and Figure I)

IPs Empress Used as a Core Material (IPS Empress Cosmo, Ivoclar Vivadent) (Table 2 and Figure 2)

\section{Composite Used as a Core Material (Figure 3)}

$3 \mathrm{M}^{\mathrm{TM}}$ Filtek $^{\mathrm{TM}} \mathrm{Z} 250$ universal restorative is an esthetic light cured composite. The composite is made of a resin composed of BIS-GMA (Bisphenol A diglycidyl ether dimethacrylates), UDMA (urethane dimethacrylates), and Bis-EMA (Bisphenol A polyethylene glicol diethrate dimethacrylate). This light-curated resin has $60 \%$ silica/ zirconia (volume). With an average particle sizes of 0.6 $\mu \mathrm{m}$, the fill particle size distribution is $0.01 \mu \mathrm{m}$ to $3.5 \mu \mathrm{m}$.
Table I Shows Composition, Properties \& Manufacturer of Cosmopost

\begin{tabular}{|l|l|}
\hline \multirow{4}{*}{ Composition } & (In weight \%) \\
\cline { 2 - 2 } & ZrO2 $+\mathrm{HfO} 2+\mathrm{Y} 2 \mathrm{O} 3>99 \% \mathrm{Y} 2 \mathrm{O} 34.5-5.4 \%$ \\
\cline { 2 - 3 } $\begin{array}{l}\text { Physical } \\
\text { Properties }\end{array}$ & $\mathrm{HfO} 2<5 \% \mathrm{Al} 2 \mathrm{O} 3<0.5 \%$ \\
\cline { 2 - 2 } & Pensity $>6.0 \mathrm{~g} / \mathrm{cm} 3$ \\
\cline { 2 - 2 } & $\begin{array}{l}\text { Plexural strength (4-point) }>800 \mathrm{~N} / \mathrm{mm} 2 \\
\text { Coefficient of thermal expansion }\left(100^{\circ}-500^{\circ}\right) 10.0 \\
\pm 1.0 \mu \mathrm{m} /(\mathrm{mK})\end{array}$ \\
\hline Manufacture & Ivoclar-Vivadent, Liechtenstein. \\
\hline
\end{tabular}

\section{Methodology}

A total of 30 Cosmoposts was used in this study. Cosmoposts were divided into three groups (10 samples each) according to the post-surface treatment received (Figure 4)

- Group I: Untreated Cosmoposts (Control).

- Group II: Sandblasting of Cosmoposts.

- Group III: Silicacoating of Cosmoposts.

Every category was further classified into two subgroups regarding core material type ( $\mathrm{n}=5$ samples) (Figure 4)

- Sub Group 1: Cosmoposts received a light cured composite core (15 samples).

- Sub Group 2: Cosmoposts received heat-pressed IPS core (15samples).

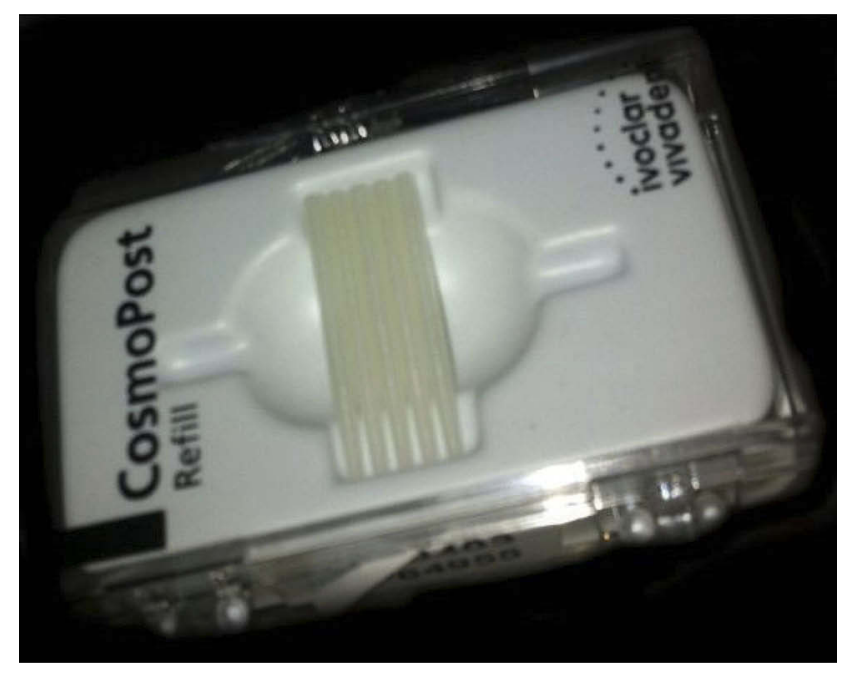

Figure I Shows cosmopost. 
Table 2 Shows Composition, Properties \& Manufacturer of IPs Empress

\begin{tabular}{|c|c|}
\hline \multirow[t]{8}{*}{ Composition } & (In weight \%) SiO2 (54-59\%) \\
\hline & ZrO2 (15 - 19\%) \\
\hline & $\mathrm{Al} 2 \mathrm{O} 3(3-7 \%)$ \\
\hline & $\mathrm{P} 2 \mathrm{O} 5$ (4 - 7\%) \\
\hline & $\mathrm{Li} 2 \mathrm{O}(7-10 \%)$ \\
\hline & $\mathrm{Na} 2 \mathrm{O}(2-5 \%)$ \\
\hline & $\mathrm{K} 2 \mathrm{O}(3-7 \%)$ \\
\hline & $F(0.5-2 \%)+$ Pigments $(0-2 \%)$ \\
\hline \multirow[t]{4}{*}{$\begin{array}{l}\text { Physical } \\
\text { Properties }\end{array}$} & $\begin{array}{l}\text { Flexural strength }>100 \mathrm{~N} / \mathrm{mm} 2 \text { Chemical solubility } \\
<2000 \mu \mathrm{g} / \mathrm{cm} 2 \text { Coefficient of thermal expansion } \\
\left(100^{\circ}-500^{\circ}\right) 9.5 \pm 0.5 \mu \mathrm{m} /(\mathrm{mK})\end{array}$ \\
\hline & $\begin{array}{l}\text { Transformation temperature } 545 \pm 10^{\circ} \mathrm{C} \text { Fracture } \\
\text { toughness [0.5-2.75 MPa] Modulus of elasticity [ } 95 \\
\text { GPa] }\end{array}$ \\
\hline & Vickers hardness [5800 MPa] \\
\hline & Press temperature $915-920 / 1679-1688\left[{ }^{\circ} \mathrm{C} /{ }^{\circ} \mathrm{F}\right]$ \\
\hline Manufacture & Ivoclar-Vivadent, Liechtenstein. \\
\hline
\end{tabular}

A specially designed copper mold was used for construction of different core materials with standardized dimensions around the posts, in such a way to ensure that the posts will be centralized. Surface roughness was estimated for all Cosmoposts, following different surface treatments using SEM. Cylindrical cores were made of composite resin or, Zirconia hot-pressed- containing glass-ceramic (IPS Empress Cosmo, Ivoclar Vivadent). Following the construction of

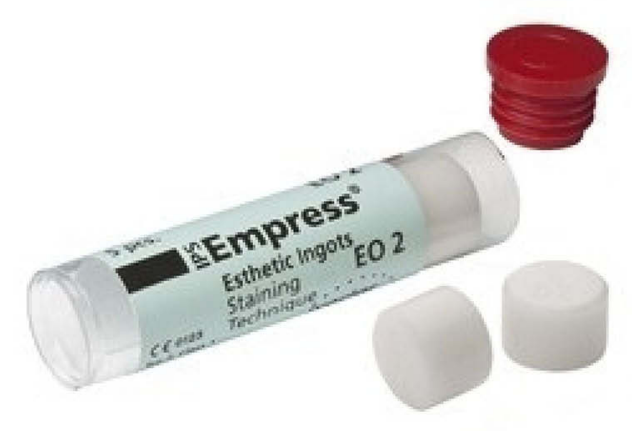

Figure 2 Shows IPS empress cosmo ingot.

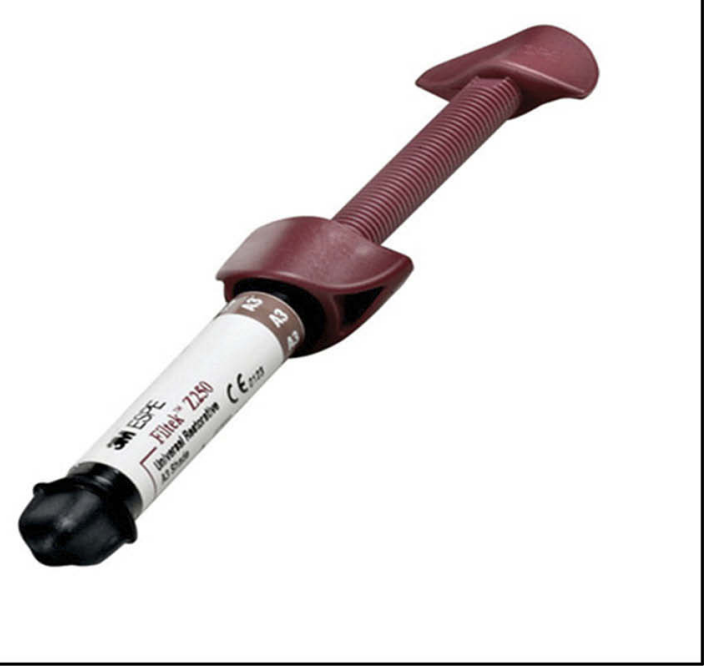

Figure 3 Shows $3 M^{\mathrm{TM}}$ filtek composite.

different Core materials, samples were subjected to push-out test set-up to assess the influence of various treatments on post/ core bond strength. Data were collected, tabulated and statistically analyzed. SEM was performed on Cosmoposts following different treatments, and following debonding of different post/core samples to determine their mode of failure.

\section{Surface Roughness Testing}

Surface roughness was estimated for all Cosmoposts, following different surface treatments using mechanical profilometer. A diamond stylus was horizontally placed into contact with the posts and passed over the posts for a given distance and contact force lateral. The diamond stylus high position produces an analog signal that is converted into a processed, analyzed and displayed digital signal. The diamond-style range of the diameter varies between 20 and $25 \mu \mathrm{m}$, and the horizontal resolution is measured by the sampling frequency of scan and data signals. Then data were recorded, tabulated and statistically analyzed. A sample from each group was subjected to scanning by SEM to show effect of different treatments on surface topography. Cosmopost samples have been placed for 3 mins with a $10-\mathrm{mA}$ current on aluminum stubs and gold-coated sputter. At magnification $\times 330$, the surfaces were checked with SEM.

\section{Testing of Shear Bond Strength}

The specimens were tested to determine the impact of various treatments on post-core bond strength following construction of several core materials. Such experiments 


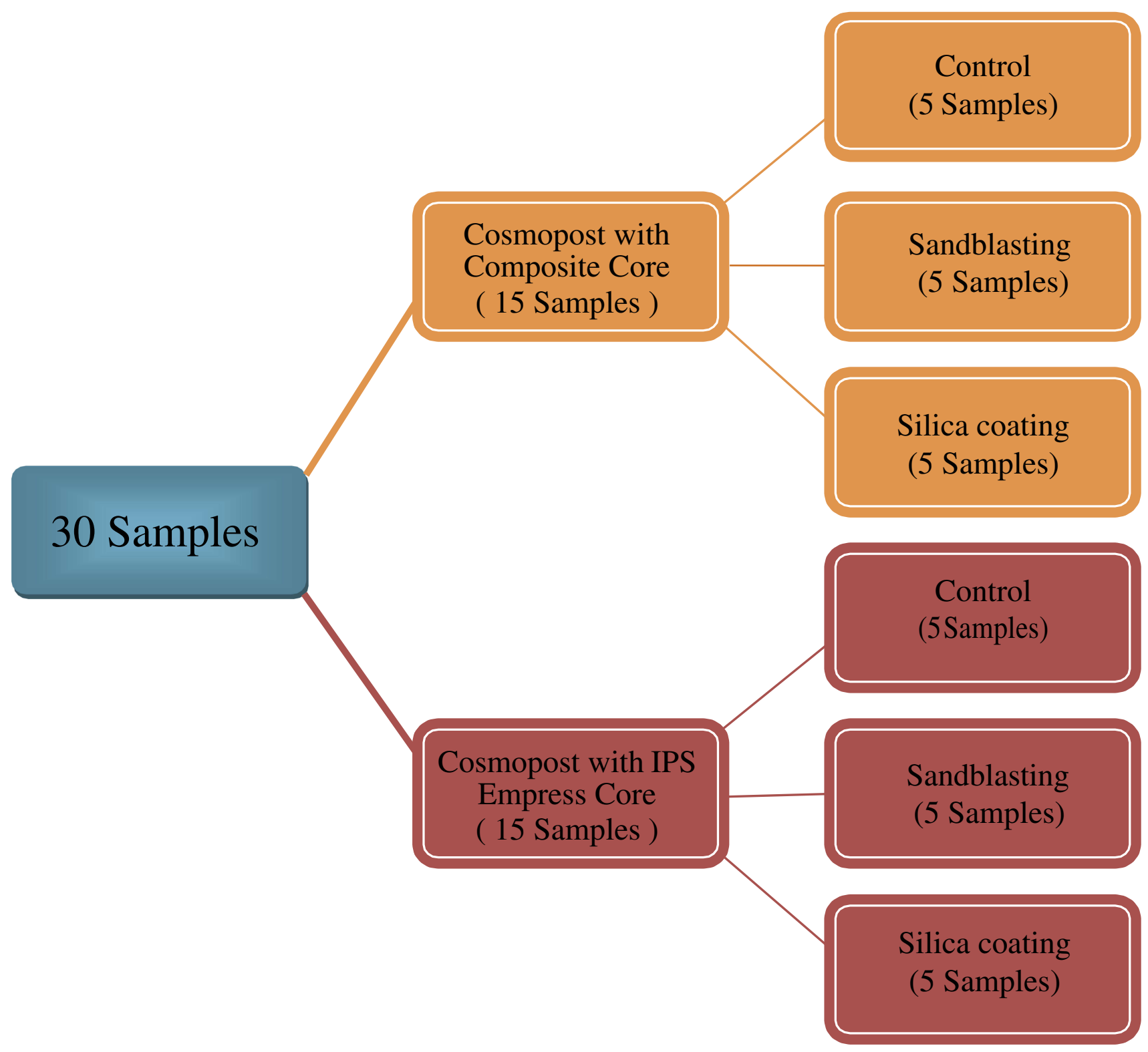

Figure 4 Flow diagram of samples grouping.

have been carried out with the universal NEXYGEN testing machine. Each core cylinder has been sealed by tightening screws to the bottom fixed compartment of a $5 \mathrm{kN}$ load cell material testing machine. The long axis of the samples was loaded by a compressive force-style shear load, with a plain-headed metal cylinder mounted on the post-heads above the composite/IPS core rings. Samples have been placed into the mold and installed in a universal test machine. A load was distributed along the long axis of the samples with a plain-headed metal cylindrical mounted on the back heads above the resin rim. The push-out pressure persisted until bond failure, detachment of the cores from the posts with a $0.5 \mathrm{~mm} / \mathrm{min}$ crosshead level by the material testing machine. A fairly slow crosshead velocity was used to create a shearing force, causing the core rings to be broken off along the interface between the core and the post. Newton recorded the debonding charge. The total failure load reported in $\mathrm{N}$ was translated to $\mathrm{MPa}$. The bond strength of the recorded peak load was measured (F) Split by the computed region (A) [as calculated by the formula (Xible et al): ${ }^{53}$

$$
\text { Bond }=\mathrm{F} / \mathrm{A},[\mathrm{A}=(\pi \mathrm{h}(2 \mathrm{r})]
$$

where $\pi$ is $3.14, \mathrm{r}$ radius, and $\mathrm{h}$ is the specimen thickness in millimeters]. 
Table 3 Comparison Between Ra Values of Surface Treatments of Composite in Microns

\begin{tabular}{|l|l|l|l|l|l|l|}
\hline \multicolumn{2}{|l|}{ Control } & \multicolumn{2}{l|}{ Silica Coating } & \multicolumn{2}{l|}{ Sandblasting } & \multirow{2}{*}{ P-value } \\
\cline { 1 - 5 } Mean & SD & Mean & SD & Mean & SD & \\
\hline $0.747^{\mathrm{a}}$ & 0.003 & $0.635^{\mathrm{b}}$ & 0.006 & $0.645^{\mathrm{b}}$ & 0.005 & $<0.001^{*}$ \\
\hline
\end{tabular}

Notes: ${ }^{\mathrm{a}}$ Untreated Cosmoposts (Control). ${ }^{\mathrm{b}}$ Cosmopost treated with silica coating, sandblasting, *Significant at $\mathrm{P} \leq 0.05$, statistically different letters are significantly different.

\section{Detecting Mode of Failure}

After the push-out test, debonded post segments are placed at $10 \mathrm{~mA}$ current on aluminum stubs and sputtered with gold palladium11 for 3 mins. Debonded post surfaces were examined with SEM at $\times 33$ magnification to assess failure mode. The analysis of three forms of fail mode: ${ }^{1}$ Adhesive breakdown at a post-core surface interface, ${ }^{2}$ Core material cohesion failure, and ${ }^{3}$ Adhesive-cohesive failure variations on a single surface or a combined failure type. Calculation, tabulation, statistical analysis.

\section{Statistical Analysis}

Data were given as mean and default (SD) values. Pushout bond strength data showed parametric distribution, so regression model using Two-way Variance Analysis (ANOVA) has been utilized to check the Importance of core material impact, surface treatment and their interactions on mean push-out bond strength. If ANOVA test is significant, the post-hoc Tukey's test was used for contrasting groups in pairs. One-way Variance Analysis
(ANOVA) was used to compare surface roughness values. The value frequency was set at 0.05 P. IBM ${ }^{\circledR}$ SPSS ${ }^{\circledR}$ Statistics Version 20 analyzed statistics.

\section{Results}

\section{Results of Surface Roughness}

Effect of Different Surface Treatments on (Ra) Values (Table 3, Figure 5)

Control group showed the statistically highest mean surface roughness $(0.747 \mu \mathrm{m})$. No statistically significant distinction was found between silica coating and sandblasting procedures; all displayed statistically lowest mean surface roughness values $(0.635 \mu \mathrm{m}$, respectively, and $0.645 \mu \mathrm{m})$.

\section{Results of Push-Out Bond Strength Effect of Different Variables Using Two-Way ANOVA results (Table 4)}

The results showed that core material, the interaction between the two parameters and surface treatment was statistically significant for mean pushout bond strength.

\section{The Influence of Type of Core Material on Push-Out Bond Strength (Table 5, Figure 6)}

Results showed that IPS Empress Cores showed statistically significantly higher mean push-out bond strength to Cosmopost (36.4 $\pm 9.7 \mathrm{MPa})$ than composite Cores (15.8 $\pm 2.5 \mathrm{MPa})$

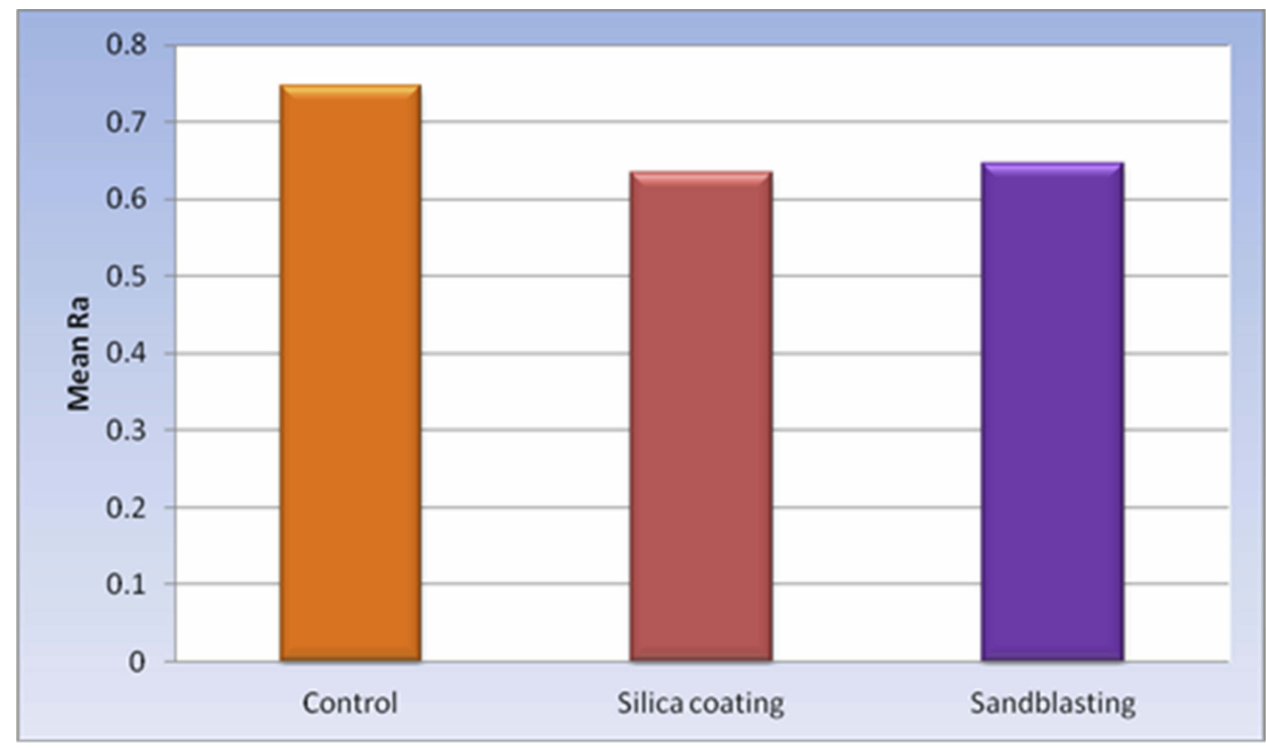

Figure 5 Bar chart representing mean values for comparison between surface roughness of different surface treatments in microns. 
Table 4 Resulted Regression Model Effect on Mean Push-Out Bond Strength of Different Variables in $\mathrm{MPa}$

\begin{tabular}{|l|l|l|l|l|l|}
\hline Source of Variation & $\begin{array}{l}\text { Type III } \\
\text { Sum of } \\
\text { Squares }\end{array}$ & Df & $\begin{array}{l}\text { Mean } \\
\text { Square }\end{array}$ & F-value & P-value \\
\hline Core material & 1541.1 & 1 & 1541.1 & 93.2 & $<0.00 I^{*}$ \\
Surface treatment & 322.1 & 2 & 161 & 9.7 & $0.004^{*}$ \\
Core material x Surface & 197.6 & 2 & 98.8 & 6 & $0.020^{*}$ \\
treatment & & 6 & & \\
\hline
\end{tabular}

Note: *Significant at $\mathrm{P} \leq 0.05$.

Abbreviation: $d f$, degrees of freedom $=(n-1)$.

Table 5 Comparison Between Push-Out Bond Strength of Core Materials (in Mpa) Regardless of Surface Treatment

\begin{tabular}{|l|l|l|l|l|}
\hline \multicolumn{2}{|l|}{ Composite } & \multicolumn{2}{l|}{ IPS Empress } & \multirow{2}{*}{ P-value } \\
\cline { 1 - 3 } Mean & SD & Mean & SD & \\
\hline 15.8 & 2.5 & 36.4 & 9.7 & $<0.00 I^{*}$ \\
\hline
\end{tabular}

Note: *Significant at $\mathrm{P} \leq 0.05$.

\section{Impact of Various Surface Treatments on the Strength of Push Out Bonds (Table 6 and Figure 7)}

Statistically no significant difference between the control group and Silica-treated one, which displayed the statistically highest mean push-out bond strength values $(27.2 \pm 14.9 \mathrm{Mpa}$ \& 28.3 $\pm 13.6 \mathrm{Mpa}$, respectively). While the Sandblasting treated group showed the statistically significantly lower mean push-out bond strength value $(18.5 \pm 5.9 \mathrm{MPa})$.

\section{Effect of Different Interactions on}

Push-Out Bond Strength (Table 7 and

\section{Figure 8)}

There was no statistically significant difference between the control group attached to IPS Empress Core (IPS Empress Control) and the silica coating group attached to IPS Empress Core (IPS Empress with Silica coating); All exhibited significantly higher mean push-out bond strength values. The Cosmoposts treated by sandblasting and attached to IPS Empress Core showed statistically significantly lower mean value.

There was no statistically significant difference between the control group attached to Composite core (Composite control), and the silica coating group attached to Composite (Composite with Silica coating) and the sandblasting group attached to Composite (Composite with Sandblasting); All displayed significantly lower mean push-out bond strength values.

\section{SEM of Differently Treated Cosmoposts}

Representative SEM photographs showing Cosmoposts with different surface treatments (Figures 9-11)

\section{Interpretation of SEM Photographs}

On viewing SEM photographs of Sandblasted group, a slightly irregular surface was revealed, together with the evidence of alumina particles embedded on the surface, as presented in (Figure 10) for Cosmopost samples.

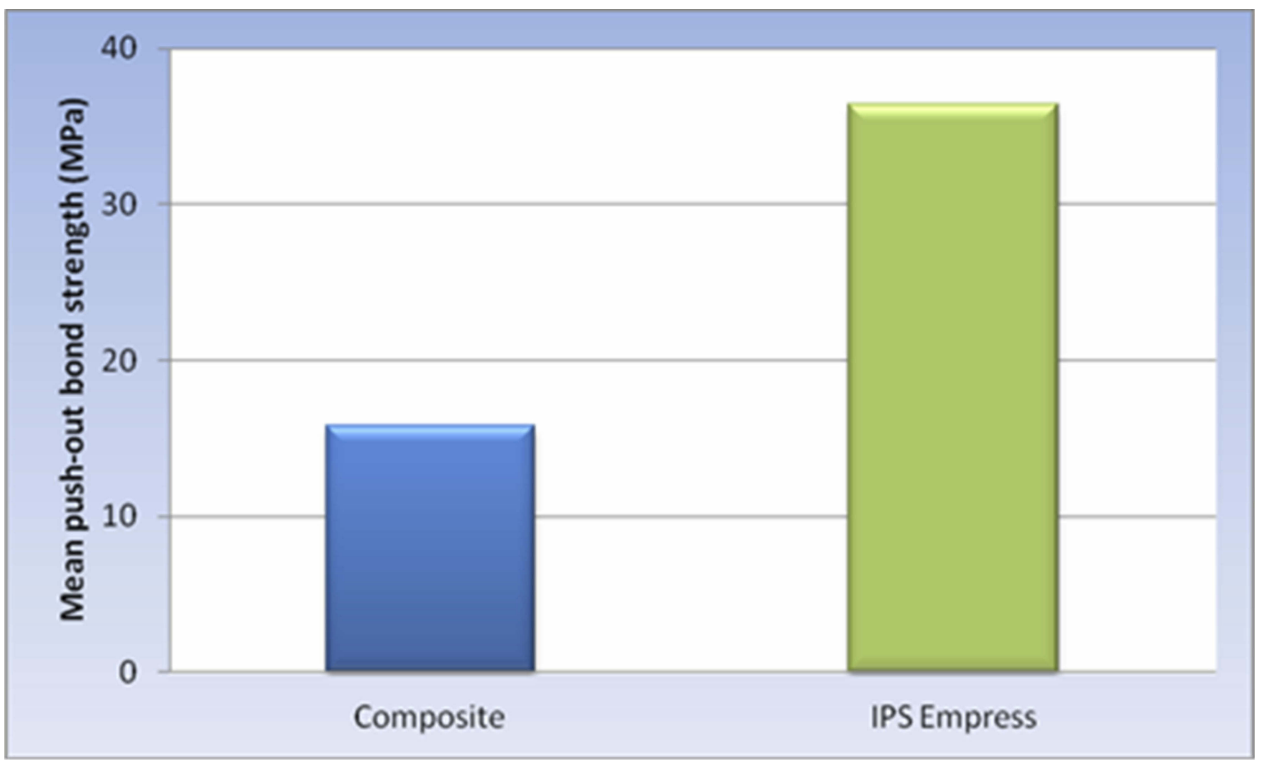

Figure 6 Row graph displaying mean values for contrast between the bond strength of the two core materials (in MPa). 
Table 6 Comparison Between Push-Out Bond Strength of Surface Treatments (in Mpa) Regardless of Core Materials

\begin{tabular}{|l|l|l|l|l|l|l|}
\hline \multicolumn{2}{|l|}{ Control } & \multicolumn{2}{l|}{ Silica Coating } & \multicolumn{2}{l|}{ Sandblasting } & \\
\hline Mean & SD & Mean & SD & Mean & SD & P-value \\
\hline $27.2^{\mathrm{a}}$ & 14.9 & $28.3 \mathrm{a}$ & 13.6 & $18.5 \mathrm{~b}$ & 5.9 & $0.004^{*}$ \\
\hline
\end{tabular}

Notes: ${ }^{a}$ Untreated Cosmoposts (Control) and Cosmoposts treated with silica coating. ${ }^{b}$ Cosmopost treated with sandblasting, *Significant at $\mathrm{P} \leq 0.05$, Statistically, different letters differ significantly.

Samples treated with silica coating, revealed relatively irregular surface with silica agglomerates precipitating on the post surface (dark gray patches) (Figure 11).

\section{Mode of Failure of Differently Treated Cosmoposts and Composite Core Rings}

SEM images of the broken interfaces are seen in figures after the push out test. ${ }^{12-14}$ Photographs show that composite resin core material was completely separated from the post surfaces in all groups (Control, sandblasting and Silica coating treated groups), Showing the composite core material with $100 \%$ adhesive fracture mode. (Figures 12-14)

\section{Mode of Failure of Differently Treated Cosmoposts and IPs Empress Core Rings} Photographs showed that de-bonded Cosmoposts are partly covered in all checked groups with Empress Core IPs. The maximum residual IPS Empress Core were calculated to be between (10-20\%) of each post area in all
Table 7 Comparison Between Push-Out Bond Strength of Different Variables' Interactions in $\mathrm{MPa}$

\begin{tabular}{|l|l|l|l|l|}
\hline Core material & Surface Treatment & Mean & SD & P-value \\
\hline \multirow{2}{*}{ Composite } & Control & $14.5^{\mathrm{c}}$ & 0.9 & \multirow{2}{*}{$0.020^{*}$} \\
& Silica coating & $18.4^{\mathrm{c}}$ & 1.2 & \\
& Sandblasting & $14.6^{\mathrm{c}}$ & 2.8 & \\
\hline \multirow{2}{*}{ IPS Empress } & Control & $39.9^{\mathrm{a}}$ & 8.2 & \\
& Silica coating & $43.2^{\mathrm{a}}$ & 0.5 & \\
& Sandblasting & $24.3^{\mathrm{b}}$ & 3.3 & \\
\hline
\end{tabular}

Notes: ${ }^{a}$ Controlled and silica coating cosmopost attached to IPS empress core. bSandblasted cosmopost attached to IPS empress core. 'Controlled, silicacoated, sandblasted cosmopost attached to composite core.*Significant at $P \leq 0.05$, Statistically, different letters differ significantly.

groups (Control, Sandblasting \& Silica coating); indicating adhesive/cohesive form failure. (Figures 15-17)

\section{Discussion}

Cosmoposts possesses superior mechanical and physical properties. Their optical properties are compatible with an all ceramic crowns. ${ }^{54}$ The rigidity of zirconium posts are sufficient, with elasticity modulus greater than stainless steel. ${ }^{55}$ Many studies have recorded a strong bending power and hard fracturing, ${ }^{56}$ radiopaque, biologically compatible and similar physical characteristics to steel. ${ }^{57}$ As this post cannot be attached, a technique has been presented by pressing a ceramic core enhanced by leucite (Empress, Ivoclar) to the all-zirconium post ${ }^{58}$ which was claimed to provide an appropriate bond between the post and core. These posts used also with a composite core material. ${ }^{30}$ Yet, the smooth

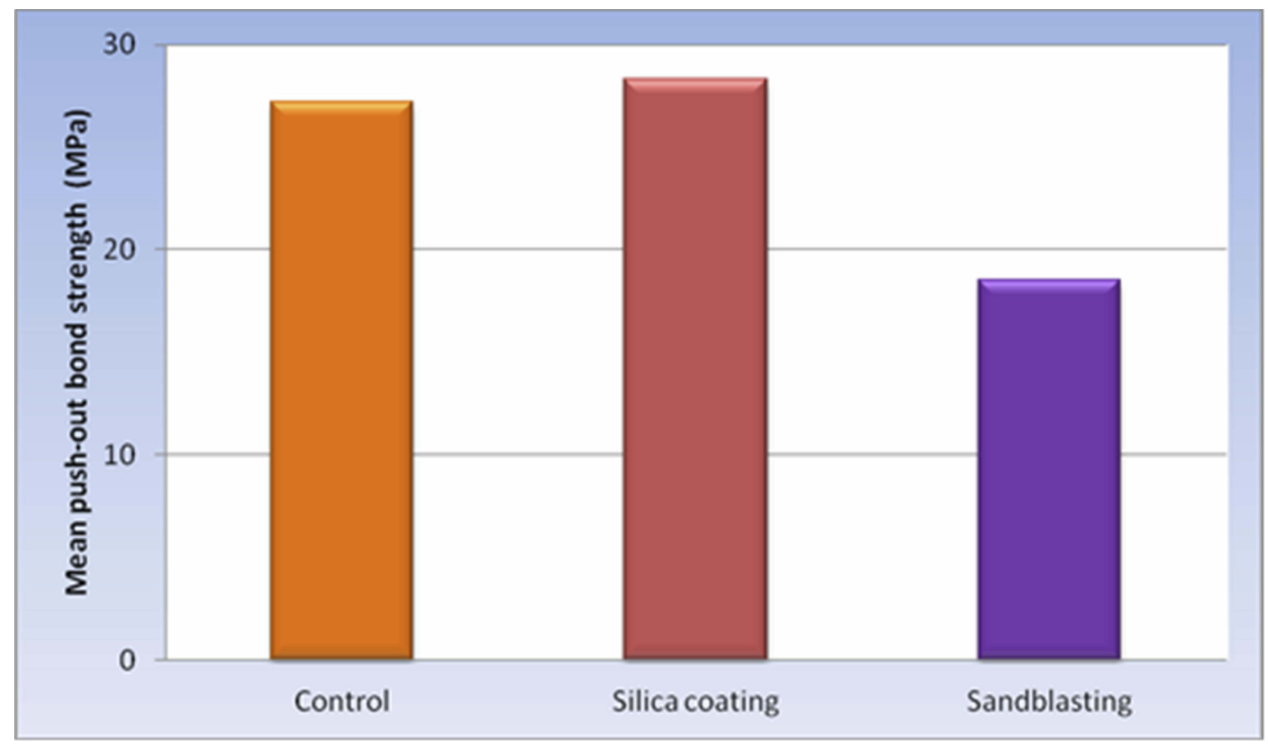

Figure 7 Row graph which shows the mean values for comparing the push-out bond strength of the different surface treatments in MPa. 


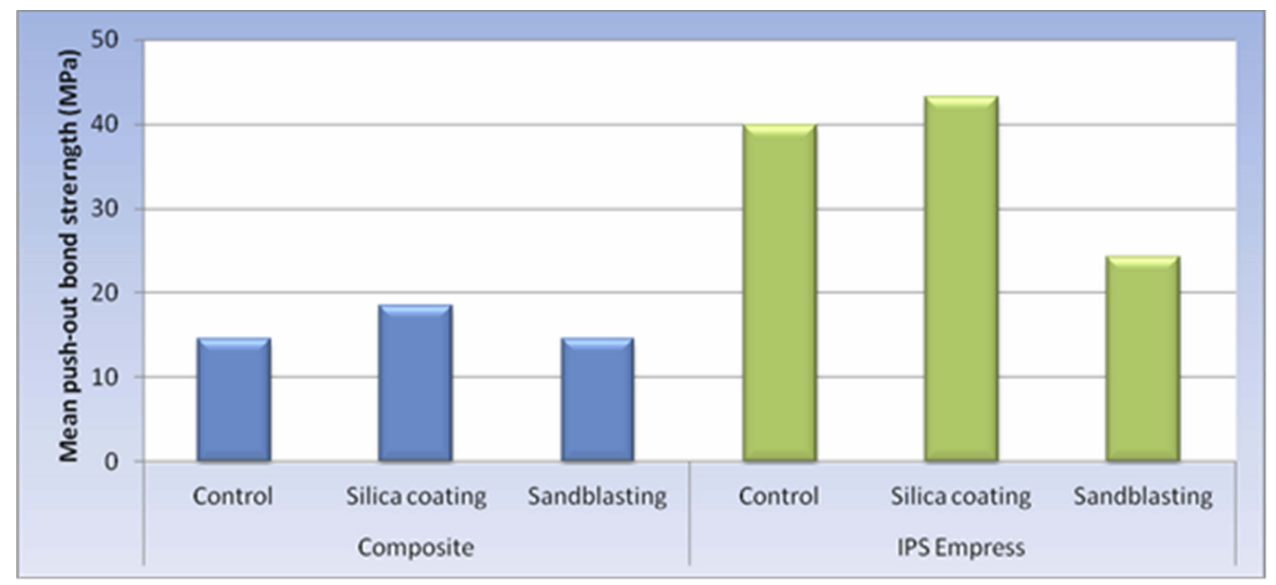

Figure 8 Row graph displaying mean values of the push-out bond strength of a different interaction (in MPa).

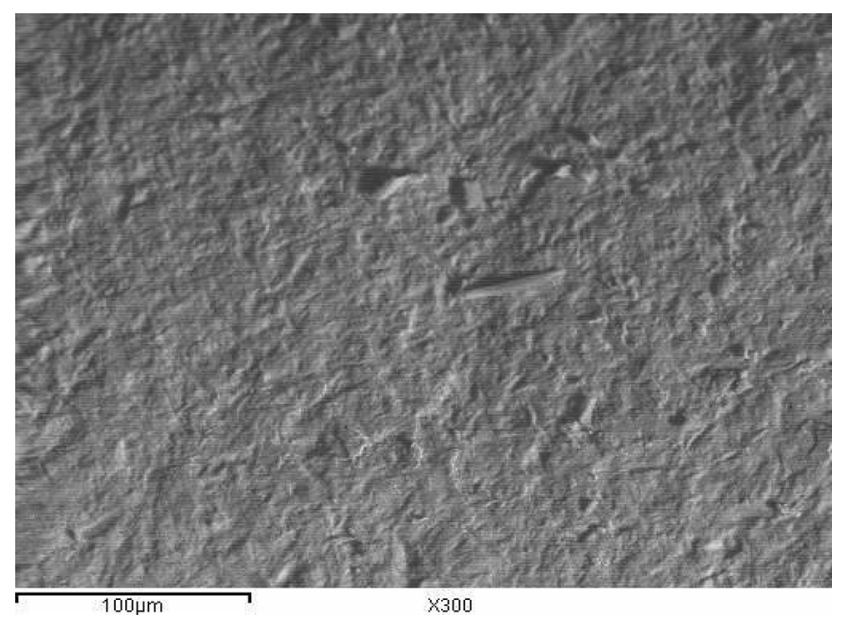

Figure 9 Photomicrograph of untreated zirconia dowel surface (original magnification 300 ).

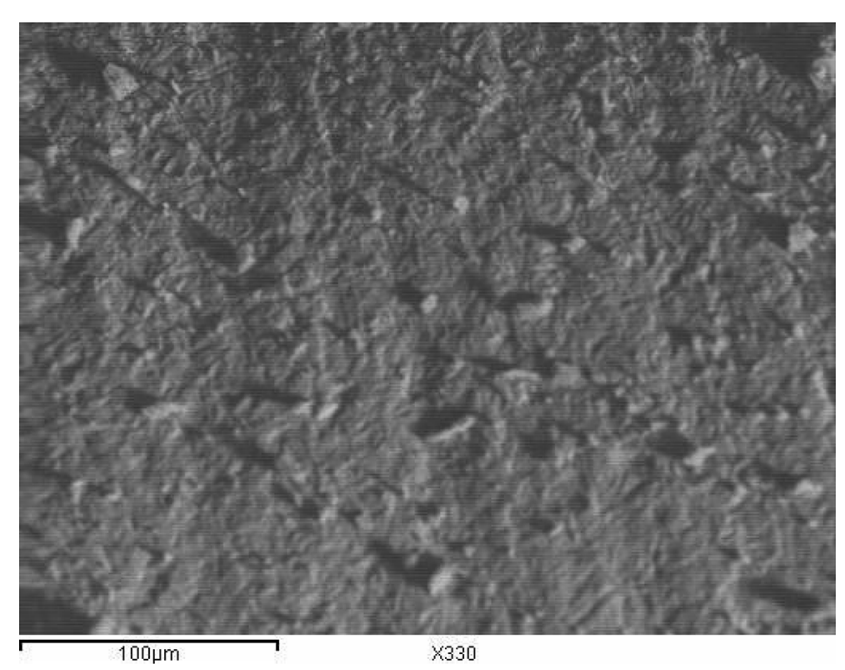

Figure 10 Photomicrograph of sandblasted cosmopost surface.

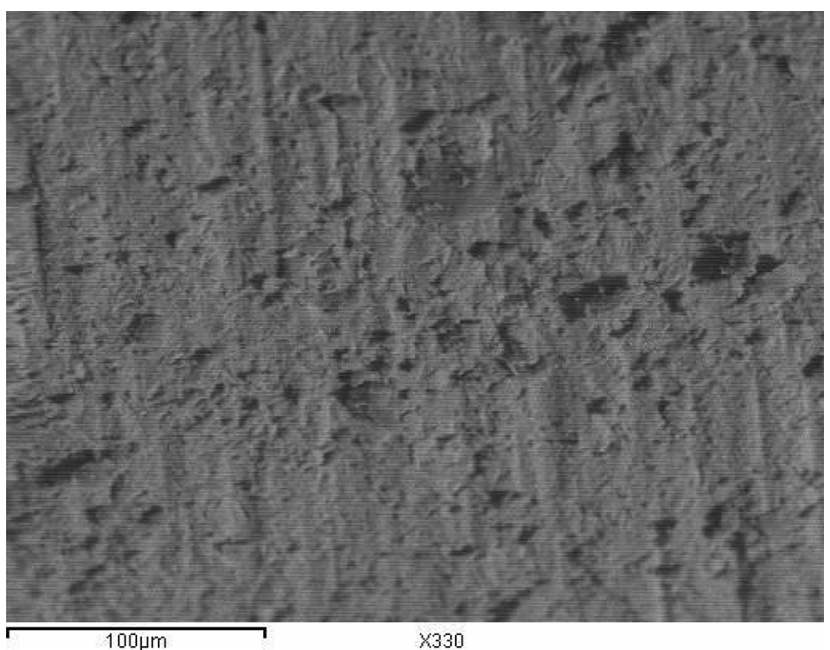

Figure II Photomicrograph of silica coated cosmoposts surface.

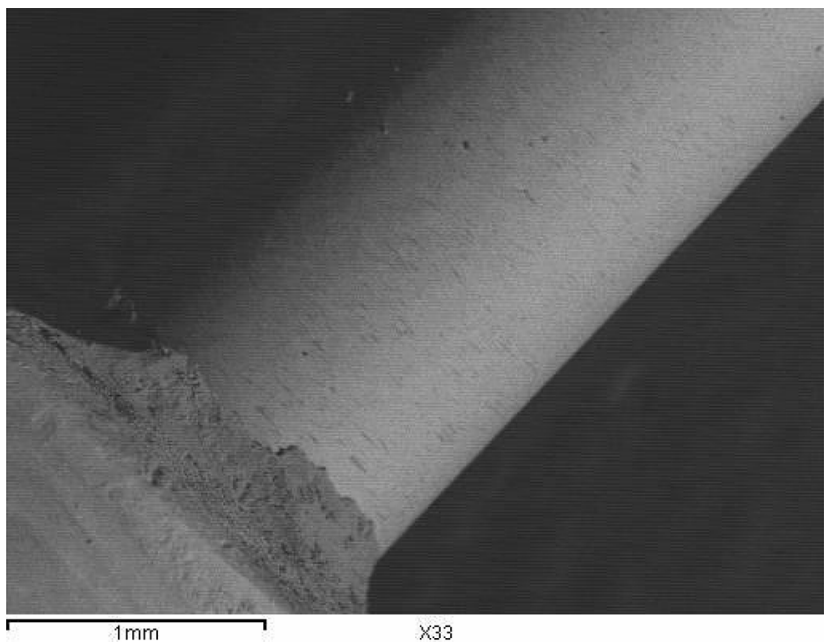

Figure 12 Representative SEM of control group attached to composite core (original magnification 33) demonstrating adhesive type of failure. 


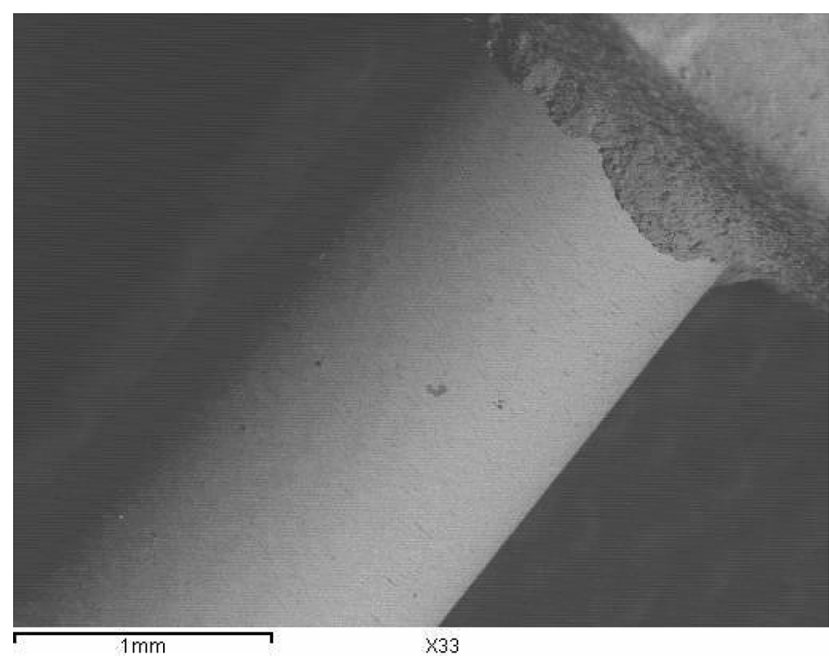

Figure 13 Representative SEM of sandblasting treated group attached to composite core (original magnification 33) demonstrating adhesive type of failure.

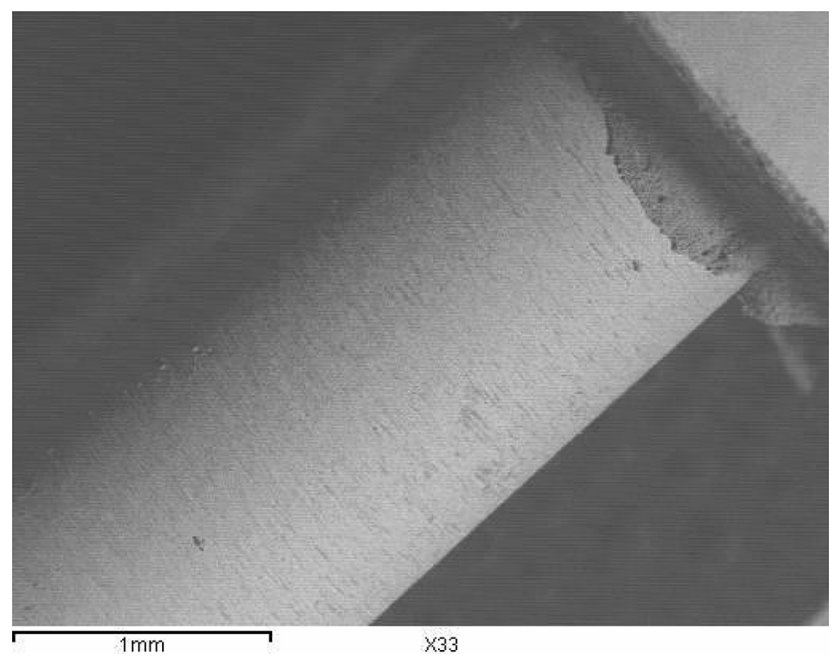

Figure I4 Representative SEM of silica coating treated group attached to composite core (original magnification 33) demonstrating adhesive type of failure.

surface of the zirconia avoids any macromechanical or micromechanical attachment to the composite cores therefore a strong bond of zirconia posts to composite resin materials is difficult to achieve and also due to the lack of silica content of zirconia posts which prohibits etching treatment to the post. Therefore, surface treatments were suggested to be tested to improve the bond strength, which will either micromechanically or chemically facilitate the ceramic bonding, ${ }^{59}$ so airborne-particle abrasion was chosen to create micromechanical interlocking between the Core materials and the Zirconia ceramic surface. ${ }^{60}$ Moreover, the reaction between the silica content of the ceramic material and the silane coupling agent responsible for the chemical bonding to the ceramic surface, ${ }^{6,7}$ so Silica coating treatment together

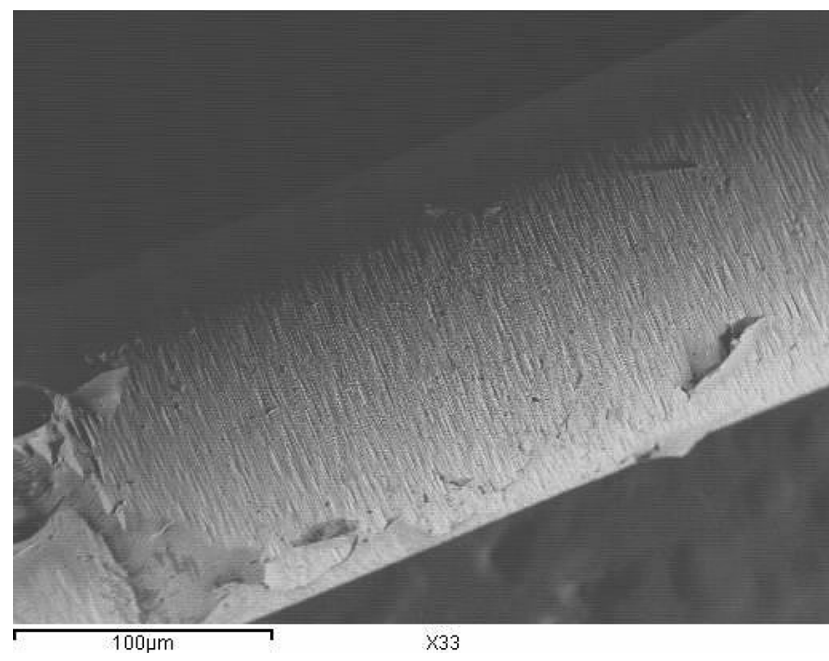

Figure 15 Representative SEM of control group attached to IPS empress core (original magnification 33) demonstrating adhesive/Cohesive type of failure.

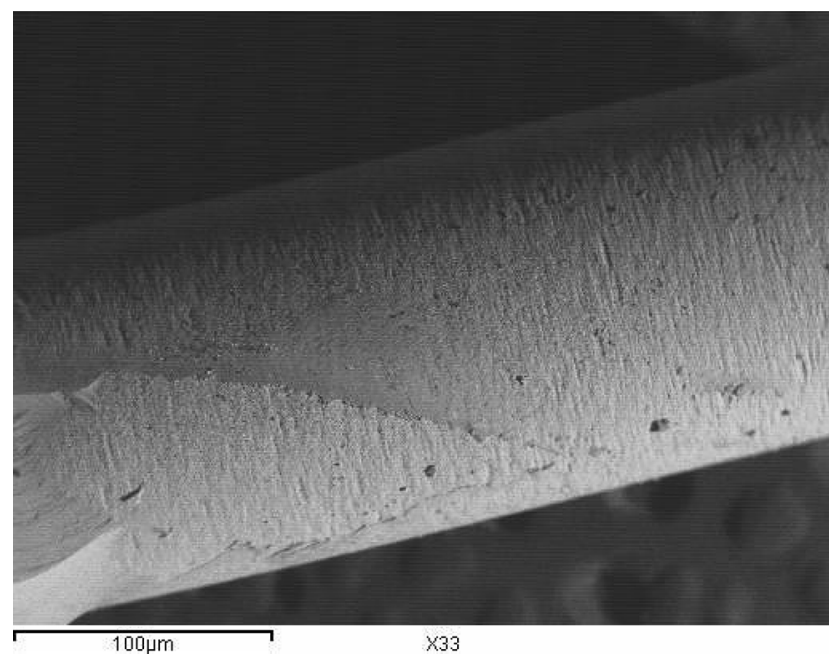

Figure 16 Representative SEM of sandblasting treated group attached to IPS empress core (original magnification 33) demonstrating adhesive/Cohesive type of failure.

with Silanization of the posts were suggested as a Chemicomechanical treatment.

Based on Ra, silicacoating and sandblasting resulted in lower Cosmopost $\mathrm{Ra}$ values and smooth surfaces. These lower $\mathrm{Ra}$ values could be explained by high zirconia ceramic surface hardness. ${ }^{61}$ In accordance with Shivaughn et al 2005, ${ }^{62}$ said Ceramic zirconia had strong toughness of Vickers (400 VHN). CosmoPosts developed only small undercuts due to its relatively high strength, reducing potential micromechanical retention with detrimental effect on bond strength as stated by Kern 1998, ${ }^{63}$ Core material, surface treatment, and a statistically significant influence on mean strength of the push-out bond as interaction between the two variables. 


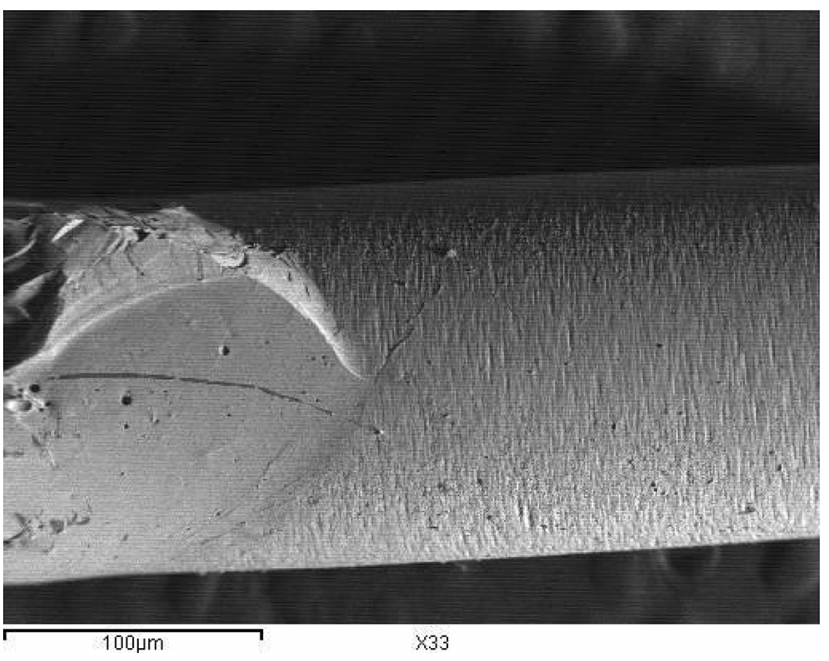

Figure 17 Representative SEM of silica coating treated group attached to IPS empress core (original magnification 33) demonstrating increased cohesive failure and less type of adhesive failure.

Results showed that IPS Empress Cores exhibited significantly higher mean push-out bond ability to Cosmopost than composite Cores, which was consistent with Kakehashi et al 1997, ${ }^{64}$ This may be because the IPs Empress expansion coefficient is slightly lower than the ZrO2-TZP ceramic. This modification of IPS Empress Como Ingot ceramic's expansion coefficient and high $\mathrm{ZrO} 2$ content [15-19 wt. Percent] allows optimum bonding to CosmoPost $\mathrm{ZrO} 2-\mathrm{TZP}$-ceramics as stated by Schweiger et al, $1998 .^{65}$ Statistically no significant difference between the control group and Silica-treated posts, both showed statistically highest mean push-out bond strength values. While the Sandblasting treated group revealed statistically significantly lower mean value pushout bond strength.

In this test, the modification induced by tribochemical treatment followed by silanization was found to improve bond strength with composite resin/IPS Empress Cores, but this improvement was not statistically significant. Two different mechanisms can contribute this increase in bond strength. First, microscopic irregularities produced by the abrasion of silica-coated airborne particles (Rocatec Plus; 3 M ESPE), which can offer retention mechanically. The second process depends on the particular processing of silica adhesive material and the application of silane. As Rocatec Plus (3 M ESPE) comprises of standard Al2O3 particles $(\mathrm{SiO} 2)$ that are frequently molded and siliconcoated. The $\mathrm{SiO} 2$ is tribochemically processed and can be attached to metal alloys or ceramics of high density. ${ }^{66,67}$ Chemical bond developed between the silica layer and composite core rings by application of silane. ${ }^{67,68}$ This suggests the effectiveness of the silica layer offered by silica-coated aluminum oxide airborne particle abrasion (Rocatec Plus); the bond strength values between composite resin/IPs Empress core rings and zirconia cosmoposts is increased. The hybrid organic-inorganic compounds of silane coupling agents can promote chemical bonds between organic and inorganic materials by means of double reactiveness. ${ }^{8,9}$ Silane coupling agents also increase ceramic surface energy and wetting capacity and thus improve the macroscopic interaction between ceramic and composite resin. ${ }^{69}$ Improve the silica content of the substrate and establish chemical silica silane binding (siloxane) ${ }^{59}$ were proposed silicacoating techniques. Mode of Failure of Debonded Various Core Materials represented the bond strength quality of each Cosmopost Core Material type. All cosmoposts bonded to composite resin core rings showed adhesive failure mode, suggesting low bond strength. Cohen et al, $2000^{48}$ Low bond strengths have been reported when binding zirconia posts to core resin composites. This finding is due to the zirconium posts' smooth surface, which prevents the macromechanical and micromechanical retention of core materials. ${ }^{48}$ Zirconium posts were therefore more vulnerable to zirconia posts and composite resin interfaces from adhesive loss. ${ }^{49}$ In addition, recent study has shown that there is less than ideal bond strength between zirconia post and composite material. ${ }^{70}$ While AdhesivelCohesive form of failure were observed in IPs Empress Core rings with Cosmopost, this was attributed to the fact that the bond between CosmoPost and IPS Empress Cosmo ingot is a ceramic-ceramic bond that can be accomplished with the common IPS Empress heat-pressing technique. The heatpressed ceramic also has a zirconia-compatible thermal expansion coefficient. ${ }^{65}$ The zirconia post and glass ceramic core used in this experiment were manufactured in the same manufacturer and optimally combined. In this initial study, the results reported were produced with static load. Clinically, however, dental restorations are more exposed than those incorporated in laboratory tests to stresses and thermal interactions. It is therefore logical that in vivo failures may occur at less stress than reported in this study, therefore further in vivo studies are recommended.

\section{Conclusions}

Within this report, the following conclusions are drawn:

- The posts are supplied with an adequately roughened surface. Therefore, they do not have to be pre-treated in the laboratory. This is consistent with this study's results. 
- For zirconia posts buildups, direct heat-pressed ceramic cores seemed more beneficial than Composite Cores, as they offered higher bond strength due to double improvement: improved fracture resistance as well as retentive strength to post.

- Tribochemical Silicacoating technique was proved to be more effective in Cosmoposts treatments than sandblasting technique.

\section{Disclosure}

The authors report no conflicts of interest in this work.

\section{References}

1. Gloriaa A, Maietta S, Martorelli M, et al. FE analysis of conceptual hybrid composite endodontic post designs in anterior teeth. Dent Mater. 2018;34(7):1063-1071. doi:10.1016/j.dental.2018.04.004

2. Edelhoff D, Sorensen JA. Retention of selected core materials to zirconia posts. Oper Dent. 2002;27(5):455-461.

3. Heydecke G, Butz F, Hussein A, Strub JR. Fracture strength after dynamic loading of endodontically treated teeth restored with different post-and-core systems. J Prosthet Dent. 2002;87(4):438-445. doi: $10.1067 / \mathrm{mpr} .2002 .123849$

4. Jeong SM, Ludwig K, Kern M. Investigation of the fracture resistance of three types of zirconia posts in all-ceramic post-and-core restorations. Int J Prosthodont. 2002;15(2):154-158.

5. O'keefe KL, Powers JM. Adhesion of resin composite core materials to dentin. Int J Prosthodont. 2001;14(5):451-456.

6. Kato $\mathrm{H}$, Matsumura $\mathrm{H}$, Ide $\mathrm{T}$, Atsuta $\mathrm{M}$. Improved bonding of adhesive resin to sintered porcelain with the combination of acid etching and a two-liquid silane conditioner. $J$ Oral Rehabil. 2001;28(1):102-108. doi:10.1046/j.1365-2842.2001.00627.x

7. Shimada Y, Yamaguchi S, Tagami J. Microshear bond strength of dual-cured resin cement to glass ceramics. Dent Mater. 2002;18:380-388. doi:10.1016/S0109-5641(01)00054-9

8. Debnath S, Wunder SL, McCool JI, Baran GR. Silane treatment effects on glass/resin interfacial shear strengths. Dent Mater. 2003;19(5):441-448. doi:10.1016/S0109-5641(02)00089-1

9. Matinlinna JP, Lassila LV, Vallittu PK. Evaluation of five dental silanes on bonding a luting cement onto silica-coated titanium. $J$ Dent. 2006;34(9):721-726. doi:10.1016/j.jdent.2006.01.005

10. Ferrari M, Vichi A, Grandini S, Goracci C. Efficacy of different adhesive technique on bonding to root canal walls. Dent Mater. 2001;17(5):422-429. doi:10.1016/S0109-5641(00)00102-0

11. Duret B, Reynaud M, Duret F. A new concept of corono-radicular reconstruction, the Composipost (2). Chir Dent Fr. 1990;60 (542):69-77.

12. King PA, Setchell DJ. An in vitro evaluation of a prototype CFRC prefabricated post developed for the restoration of pulpless teeth J Oral Rehabil. 1990;17:599-609. doi:10.1111/j.1365-2842.1990. tb01431.x

13. de Rijk WG. Removal of fiber posts from endodontically treated teeth. Am J Dent. 2000;13(SpecNo):19B-21B.

14. Meyenberg KH, Luthy H, Schaerer P. Zirconia posts: a new all-ceramic concept for nonvital abutment teeth. $J$ Esthet Dent. 1995;7:73-80. doi:10.1111/j.1708-8240.1995.tb00565.x

15. Piconi C, Maccauro G. Zirconia as a ceramic biomaterial. Biomaterials. 1999;20(1):1-25. doi:10.1016/S0142-9612(98)00010-6

16. Ahmad I. Yttrium-partially stabilized zirconium dioxide posts: an approach to restoring coronally compromised non vital teeth. Int J Period Rest Dent. 1998;18(5):454-465.
17. Vichi A, Ferrari M, Davidson CL. Influence of ceramic and cement thickness on the masking of various types of opaque posts. J Prosthet Dent. 2000;83(4):412-417. doi:10.1016/S00223913(00)70035-7

18. Mannocci F, Ferrari M, Watson TF. Intermittent loading of teeth restored using quartz fiber, carbon-quartz fiber, and zirconium dioxide ceramic root canal posts. J Adhes Dent. 1999;1(2):153-158.

19. Satterthwaite JD, Stokes AN, Frankel NT. Potential for temperature change during application of ultrasonic vibration to intra-radicular posts. Eur J Prosthodont Rest Dent. 2003;11:51-56.

20. Luthardt RG, Musil R. Advanced ceramics and CAD/CAM technology in dentistry: the question of technological machinability of dental zirconia ceramic. Swiss Dent. 1996;11-S:37-41.

21. Christensen GJ. When to use fillers, build-ups or posts and cores. JADA. 1996;127(9):1397-1398. doi:10.14219/jada.archive.1996. 0459

22. Morgano SM, Brackett SE. Foundation restorations in fixed prosthodontics: current knowledge and future needs. J Prosthet Dent. 1999;82(6):643-657. doi:10.1016/S0022-3913(99)70005-3

23. Kovarik RE, Breeding LC, Caughman WF. Fatigue life of three core materials under simulated chewing conditions. J Prosthet Dent. 1992;68(4):584-590. doi:10.1016/0022-3913(92)90370-P

24. Craig RG, Ward ML. Restorative Dental Materials. 10th ed. St Louis: Mosby; 1997:137.

25. Larson TD, Jensen JR. Microleakage of composite resin and amalgam core material under complete cast crowns. J Prosthet Dent. 1980;44(1):40-44. doi:10.1016/0022-3913(80)90044-X

26. Hormati AA, Denehy GE. Microleakage of pin-retained amalgam and composite resin bases. J Prosthet Dent. 1980;44(5):526-530. doi:10.1016/0022-3913(80)90072-4

27. Kanca J. Dental adhesion and the all-bond system. $J$ Esthet Dent. 1991;3:129-132. doi:10.1111/j.1708-8240.1991.tb00984.x

28. Lo CS, Millstein PL, Nathanson D. In vitro shear strength of bonded amalgam cores with and without pins. J Prosthet Dent. 1995;74 (4):385-391. doi:10.1016/S0022-3913(05)80379-8

29. Oliva RA, Lowe JA. Dimensional stability of silver amalgam and composite used as core materials. J Prosthet Dent. 1987;57 (5):554-559. doi:10.1016/0022-3913(87)90335-0

30. Braem MJ, Davidson CL, Lambrechts P, Vanherle G. In vitro flexural fatigue limits of dental composites. $J$ Biomed Mat Res. 1994;28:1397-1402. doi:10.1002/jbm.820281203

31. Indrani DJ, Cook WD, Televantos F, Tyas MJ, Harcourt JK. Fracture toughness of water-aged resin composite restorative materials. Dent Mater. 1995;11(3):201-207. doi:10.1016/0109-5641(95)80019-0

32. Dionysopoulos P, Kotsanos N, Koliniotou-Koubia E, Papagodiannis Y. Secondary caries formation in vitro around fluoride-releasing restorations. Oper Dent. 1994;19(5):183-188.

33. Yaman P, Thorsteinsson TS. Effect of core materials on stress distribution of posts. J Prosthet Dent. 1992;68(3):416-420. doi:10.1016/ 0022-3913(92)90403-W

34. Levartovsky S, Kuyinu E, Georgescu M, Goldstein GR. A comparison of the diametral tensile strength, the flexural strength, and the compressive strength of two new core materials to a silver alloy-reinforced glass-ionomer material. J Prosthet Dent. 1994;72 (5):481-485. doi:10.1016/0022-3913(94)90118-X

35. Cohen BI, Deutsch AS, Condos S, Musikant BL, Scherer W. Compressive and diametral tensile strength of titanium-reinforced composites. $J$ Estliet Dent. 1992;4:50-55. doi:10.1111/j.17088240.1992.tb00720.x

36. Cohen BI, Condos S, Deutsch AS, Musikant BL. Fracture strength of three different core materials in combination with three different endodontic posts. Int Prosthodont. 1994;7(2):178-182.

37. Cohen BI, Pagnillo MK, Condos S, Deutsch AS. Four different core materials measured for fracture strength in combination with five different designs of endodontic posts. J Prosthet Dent. 1996;76 (5):487-495. doi:10.1016/S0022-3913(96)90006-2 
38. Cohen BI, Pagnillo MK, Newman I, Musikarit BL, Deutsch AS. Cyclic fatigue testing of five endodontic post designs supported by four core materials. J Prosthet Dent. 1997;78(5):458-464. doi:10.1016/S0022-3913(97)70060-X

39. Strub JR, Türp JC, Witkowski S, Hürzeler MB, Kern M. Curriculum Prothetik. 2nd ed. Berlin: Quintessenz; 1994.

40. Paul S, Schärer P. Plastische Aufbauten in der Kronen- und Brückenprothetik. Quintessenz. 1996;47(11):1519-1531.

41. Strub JR, Türp JC, Blatz MB, Heydecke G. Vorbehandlung. In: Keoch B, editor. Kronen- Und Brückenprothetik. München: Urban und Schwarzenberg; 1999;5:234-255.

42. Millstein PL, Ho J, Nathanson D. Retention between a serrated steel dowel and different core materials. J Prosthet Dent. 1991;65 (4):480-482. doi:10.1016/0022-3913(91)90283-3

43. Eichner K, Kappert H. Zahnärzliche Werkstoffe und ihre verarbeitung. 6th ed. Heidelberg: Hüthig GmbH; 1996.

44. Sornkul E, Stannard JG. Strength of roots before and after endodontic treatment and restoration. J Endod. 1992;18(9):440-443. doi:10.1016/ S0099-2399(06)80845-9

45. Lanzano JA, Mastrodomenico J, Gwinnett AJ. Strength of amalgam restorations bonded with amalgambond. Am J Dent. 1993;6(1):10-12.

46. Ruzickova T, Staninec M, Marshall GW, Hutton JE. Bond strengths of the adhesive resin-amalgam interface. Am J Dent. 1997;10 (4):192-194

47. Pilo R, Cardash HS, Levin E, Assif D. Effect of core stiffness on the in vitro fracture of crowned, endodontically treated teeth. J Prosthet Dent. 2002;88(3):302-306. doi:10.1067/mpr.2002.127909

48. Cohen BI, Pagnillo MK, Newman I, Musikant BL, Deutsch AS. Retention of a core material supported by three post head designs. J Prosthet Dent. 2000;83(6):624. doi:10.1067/mpr.2000.107228

49. Al-harbi F, Nathanson D. In vitro assessment of retention of four esthetic dowels to resin core foundation and teeth. J Prosthet Dent. 2003;90(6):547-555. doi:10.1016/j.prosdent.2003.09.014

50. Jain G, Narad A, Boruah L, et al. Comparative evaluation of shear bond strength of three resin based dual-cure core build-up materials: an in-vitro study. J Cons Dent. 2015;18(4):337-341. doi:10.4103/ 0972-0707.159754

51. Paul SJ, Werder P. Clinical success of zirconium oxide posts with resin composite or glass-ceramic cores in endodontically treated teeth: a 4-year retrospective study. Inter J Prosthod. 2004;17(5):524-528.

52. Nothdurft FP, Pospiech PR. Clinical evaluation of pulpless teeth restored with conventionally cemented zirconia posts: a pilot study. J Prosthet Dent. 2006;95(4):311-314. doi:10.1016/j.prosdent.2006.02.024

53. Xible AA, de Jesus Tavarez RR, de Araujo Cdos R, Bonachela WC. Effect of silica coating and silanization on flexural and composite-resin bond strengths of zirconia posts: an in vitro study. J Prosthet Dent. 2006;95(3):224-229. doi:10.1016/j.prosdent.2005. 12.010

54. Zalkind M, Hochman N. Esthetic considerations in restoring endodontically treated teeth with posts and cores. J Esthet Dent. 1996;8 (3):101-106
55. Rovatti L, Cavalleri G, Dallari A. A new matrix in esthetic posterior restorations. Compend Contin Educ Dent. 1998;19(3):332,334, 6.

56. Hulbert SF, Morrison SJ, Klawitter JJ. Tissue reaction to three ceramics of porous and nonporous structure. J Biomed Mater Res. 1972;6:347-374. doi:10.1002/jbm.820060505

57. Ichikawa Y, Akagawa Y, Nikai H, Tsuru H. Tissue compatibility and stability of a new zirconia ceramic in vivo. J Prosthet Dent. 1992;68 (2):322-326. doi:10.1016/0022-3913(92)90338-B

58. Hochman N, Zalkind M. New all-ceramic indirect post-and-core system. J Prosthet Dent. 1999;81(5):625-629. doi:10.1016/S00223913(99)70220-9

59. Amaral R, Ozcan M, Bottino MA, Valandro LF. Microtensile bond strength of a resin cement to glass infiltrated zirconia-reinforced ceramic: the effect of surface conditioning. Dent Mater. 2006;22 (3):283-290. doi:10.1016/j.dental.2005.04.021

60. Della Bona A, Donassollo TA, Demarco FF, et al. Characterization and surface treatment effects on topography of a glass- infiltrated alumina/zirconia-reinforced ceramic. Dent Mater. 2007;23 (6):769-775. doi:10.1016/j.dental.2006.06.043

61. Kern M, Wegner SM. Bonding to zirconia ceramic: adhesion methods and their durability. Dent Mater. 1998;14(1):64-71. doi:10.1016/ S0109-5641(98)00011-6

62. Shivaughn M, Larry C, Robert W, Salvacion B. In vitro evaluation of the retention of zirconia-based ceramic posts luted with glass ionomer and resin cements. Braz Dent J. 2005;16(3):213-217. doi:10.1590/S0103-64402005000300008

63. Bitter K, Priehn K, Martus P, Kielbassa AM. In vitro evaluation of push-out bond strengths of various luting agents to tooth-colored posts. J Prosthet Dent. 2006;95(4):302-310. doi:10.1016/j. prosdent.2006.02.012

64. Kakehashi X, Lüthy H, Wohlwend A, Loeffel O, Schärer P, Edelhoff D, Sorensem JA. Retention of selected core materials to zirconia posts. Oper Dent2002 sept-oct;27(5):455-61.

65. Schweiger M, Frank M, Cramer van Clausbruch S, Höland W, Rheinberger V. Microstructure and Properties of a Pressed GlassCeramic Core to a Zirconia Post. QDT; 1998a:73-79.

66. Kern N, Thompson VP. Bonding to glass-infiltrated alumina ceramic: adhesive methods and their durability. $J$ Prosthet Dent. 1995;73:240-249. doi:10.1016/S0022-3913(05)80200-8

67. Blixt M, Adamczak E, Linden L, Oden A, Arvidson K. Bonding to densely sintered alumina surfaces: effect of sandblasting and silica coating on shear bond strength of luting cements. Int J Prosthodont. 2000;13(3):221-226.

68. Wegner SM, Kern M. Long-term resin bond strength to zirconia ceramic. J Adhes Dent. 2000;2(2):139-147.

69. Valandro LF, Della Bona A, Antonio bottino M, Neisser MP. The effect of ceramic surface treatment on bonding to densely sintered alumina ceramic. J Prosthet Dent. 2005;93(3):253-259. doi:10.1016/ j.prosdent.2004.12.002

70. Dietschi D, Romelli M, Goretti A. Adaptation of adhesive posts and cores to dentin after fatigue testing. Int J Prosthodont. 1997;10 (6):498-507.

\section{Publish your work in this journal}

Clinical, Cosmetic and Investigational Dentistry is an international, peer-reviewed, open access, online journal focusing on the latest clinical and experimental research in dentistry with specific emphasis on cosmetic interventions. Innovative developments in dental materials, techniques and devices that improve outcomes and patient satisfaction and preference will be highlighted. The manuscript management system is completely online and includes a very quick and fair peer-review system, which is all easy to use. Visit http://www.dovepress.com/testimonials.php to read real quotes from published authors. 